\title{
VARIABILIDADE ESPACIAL DA UMIDADE DO SOLO EM IRRIGAÇÃO POR GOTEJAMENTO SOB CULTIVO PROTEGIDO ${ }^{1}$
}

\author{
Ivana Fúrio Batista \\ Célia Regina Lopes Zimback \\ Juliana Aguiar Vettorato \\ Departamento de Recursos Naturais, Faculdade de Ciências Agronômicas, Universidade Estadual \\ Paulista, Botucatu, CP 237, CEP 18603-970.E-mail: ivana@fca.unesp.br
}

\section{RESUMO}

Foi estudada a variabilidade espacial da umidade do solo num sistema de irrigação por gotejamento em uma estufa $(5,0 \times 20,0 \mathrm{~m})$ na Fazenda Experimental São Manuel, da Faculdade de Ciências Agronômicas, Universidade Estadual Paulista, Estado de São Paulo, Brasil. Foi estabelecida a malha de amostragem no espaçamento de $1,0 \times 0,5 \mathrm{~m}$, acrescida de quatro adensamentos de $0,25 \mathrm{~m}$. Foram utilizados dados da umidade do solo em 178 pontos. A análise da dependência espacial foi obtida com o auxílio do Programa GS+. Foi construído o variograma experimental e definido o modelo de ajuste, de modo que a curva que melhor se ajustou aos pontos obtidos representasse a magnitude, alcance e intensidade da variabilidade espacial da variável estudada. A umidade do solo apresentou distribuição espacial anisotrópica. Para a direção $0^{\circ}$, pode-se notar uma dependência espacial caracterizada como alta, com o alcance de aproximadamente $3,30 \mathrm{~m}$, no sentido do comprimento da estufa. Entretanto, no sentido da largura da estufa, não foi possível ajustar modelos. Utilizando a representação gráfica da superfície, a área estudada apresentou um maior teor de água na parte inicial e menor na parte final das linhas de distribuição de água. A krigagem mostrou-se um bom interpolador para mapeamento da umidade do solo.

UNITERMOS: geoestatística, dependência espacial, umidade do solo, irrigação por gotejamento, cultivo protegido.

\section{BATISTA, I.F.; ZIMBACK, C.R.L.; VETTORATO, J.A. SPATIAL VARIABILITY OF SOIL MOISTURE IN A DRIP IRRIGATION SYSTEM UNDER GREENHOUSE}

\section{ABSTRACT}

Soil moisture spatial variability in a drip irrigation system was studied in a greenhouse $(5.0 \mathrm{x}$ 20.0m) at São Manuel Experimental Farm, FCA/UNESP, Botucatu - SP, Brazil. Sampling was established in a $1.0 \times 0.5 \mathrm{~m}$ grid, increased $0.25 \mathrm{~m}$ thickening. Soil moisture data were used in 178

\footnotetext{
${ }^{1}$ Trabalho desenvolvido junto ao Grupo de Estudos e Pesquisas Agrárias Georreferenciadas - GEPAG. Extraído da dissertação de Mestrado da primeira autora, apresentada à FCA/UNESP
} 
points. The spatial dependence analysis was obtained with the aid of the GS+ Program. The experimental variogram was built and the setting model defined, so that the curve better fitted to the obtained points represented the spatial variability magnitude, range and intensity of the studied variable. Soil moisture presented anisotropic spatial distribution. Spatial dependence was noticed for $0^{\circ}$ direction, characterized as high, with approximately $3.30 \mathrm{~m}$ range in the greenhouse length ward. However, in the greenhouse width ward, it was not possible to fit models. Using the surface graphic representation, the studied area presented higher water content in the initial part and a lower one in the final part of water distribution lines. Kriging was shown to be a good interpolator for soil moisture mapping.

KEYWORDS: geostatistics, spatial dependence, soil moisture, drip irrigation, greenhouse.

\section{INTRODUÇÃO}

A preocupação com a variabilidade espacial do solo pode ser encontrada em trabalhos da primeira metade do século passado, mas só recentemente foi possível a incorporação da geoestatística na descrição da variabilidade de forma coerente, tanto na teoria, como na prática.

Nos últimos anos, observou-se um avanço nas áreas de monitoramento por satélite, dos registros georreferenciados e da informática, o que possibilitou o surgimento de uma nova concepção de manejo dos recursos na agricultura. Com o advento das técnicas de agricultura de precisão, observa-se um grande conjunto de práticas agrícolas altamente adaptadas às condições de ambiente e variabilidades das propriedades do solo, objetivando o aumento de lucratividade $\mathrm{e}$ redução dos impactos ambientais.

Diversos estudos têm sido realizados com a finalidade de avaliar a variabilidade espacial de atributos relacionados ao comportamento da água, como: propriedades de água-solo (NIELSEN et al., 1973), processo de infiltração de água em solos (SISSON \& WIERENGA, 1981), nível do lençol freático (ABOUFIRASSI \& MARINO, 1983), condutividade hidráulica dos solos (BRESLER et al., 1984 e CIOLLARO \& ROMANO, 1995), medidas de umidade e temperatura superficiais do solo (DAVIDOFF \& SELIM, 1988), retenção de água (BURDEN \& SELIM, 1989, VOLTZ \& GOULARD, 1994 e MALLANTS et al., 1996), velocidade de infiltração básica (SALES, 1992) e estabilidade temporal, umidade do solo e armazenamento de água (FOLEGATTI, 1996).

O conhecimento da variabilidade da umidade é de fundamental importância para que sistemas de irrigação por gotejamento sejam dimensionados segundo a necessidade de uma cultura numa determinada estufa.

O sistema de irrigação por gotejamento surgiu em 1940 na Inglaterra, onde era utilizado na irrigação e fertilização de cultivo em estufas. Porém, sua utilização no campo se deu por volta de 1950, em Israel. A partir de 1960, o gotejamento sofreu grande desenvolvimento, sendo utilizado como prática rotineira na Austrália, Europa, Israel, México, República Sul Africana e Estados Unidos (KARMELI e KELLER, 1975, citados por LEITE JÚNIOR, 2000).

Bernardo (1995) salienta que a aplicação d'água ao solo, na irrigação por gotejamento, é sob a forma de "ponto forte", ficando a superfície do solo com uma área molhada com forma circular e o volume do solo molhado com forma de um bulbo. Quando os pontos de gotejamento são próximos uns dos outros, forma-se uma faixa molhada contínua. Sendo assim, somente uma pequena porção da superfície do solo será molhada, o que diminui em muito a evaporação direta da água do solo para a atmosfera, quando comparada com a irrigação por aspersão e superfície.

BRASIL (1987) ressalta que os custos com tubulações e energia são reduzidos, devido ao fato da irrigação por gotejamento limitar a 
aplicação de água a locais específicos em porções diárias, de modo a repor sua perda pela planta e pelo solo, aliado ao fato do desenvolvimento do cultivo protegido.

A expressão cultivo protegido tem sido utilizada, na literatura internacional, com um significado bastante amplo. Ela engloba um conjunto de práticas e tecnologias (quebraventos, mulches de solo, casas de vegetação, túneis altos, túneis baixos, irrigação, etc.), utilizados pelos produtores para um cultivo mais seguro e protegido de suas lavouras (WITTWER \& CASTILLA, 1995, citados por DELLA VECCHIA \& KOCH, 1999).

No Brasil, Goto (1997) relata que as primeiras citações da utilização do plástico no cultivo de hortaliças são referentes aos trabalhos pioneiros realizados em 1967, que abordam a eficiência da utilização do plástico na cultura do morango para cobertura dos canteiros. Já com relação à utilização do plástico em estruturas, com finalidade de proteção contra adversidades climáticas, menciona que há trabalhos realizados em Manaus (AM), no final da década de 1970, que provaram a eficiência da utilização desse material na produção de hortaliças. Finalmente, Goto (1997) ressalta que em meados da década de 1980, no estado do Rio Grande do Sul, o Projeto São Tomé, apoiado pela indústria de filmes plásticos e, concomitantemente, no Estado de São Paulo, a utilização da técnica de cultivo de hortaliças em ambiente protegido por produtores cooperados da extinta Cooperativa Agrícola de Cotia na região do cinturão verde da cidade de São Paulo.

Sganzerla (1997) também relata que no Brasil, na década de 1980 a 1990, objetivando a difusão da plasticultura, houve uma iniciativa nos estados do Rio Grande do Sul, Santa Catarina, Paraná e São Paulo através do desenvolvimento do Projeto São Tomé, em meados da década de 1980 . Nesse projeto, os resultados obtidos com as culturas desenvolvidas dentro das estufas foram de extrema surpresa e incredibilidade. Houve um entusiasmo muito grande em função dos ótimos resultados. A estufa foi uma agradável novidade que apareceu e atraiu a atenção de muitas pessoas até mesmo ligadas a outras atividades.
Goto (1997) concluiu que existe grande perspectiva para os cultivos protegidos, pois esta é uma tecnologia bastante utilizada em algumas regiões e os produtores que estão desde o início ou há pelo menos cinco anos na atividade não vão retroceder e tão pouco pretendem voltar a cultivar somente em campo aberto. Considera ainda a existência de uma grande perspectiva de expansão desta tecnologia, que é capaz de utilizar pequenas áreas e produzir pelo menos uma vez e meia ao dobro do que se consegue produzir em campo aberto, desde que se saiba manejar a estrutura e o ambiente em questão, respeitando a espécie a ser instalada.

A variabilidade espacial da umidade necessita ser considerada, uma vez que o manejo da água está diretamente relacionado com as exigências hídricas das diversas culturas, com as características hidráulicas dos diferentes sistemas de irrigação utilizados e, principalmente, com a capacidade de retenção da água pelo solo, na profundidade efetiva do sistema radicular da cultura em questão. $\mathrm{Na}$ plasticultura é notável a importância da utilização da irrigação, repondo a água consumida, tornando-se um fator de garantia da produção agrícola. Em cultivos protegidos, o sistema de gotejamento é preferido, não somente pela economia de água, mas também pelo fato de ser um sistema que não molha a superfície das folhas, sendo utilizado na grande maioria das culturas, principalmente as que são suscetíveis ao ataque de fungos.

O objetivo do trabalho foi estudar a variabilidade espacial da umidade do solo, submetido à irrigação por gotejamento, em condições de cultivo protegido.

\section{MATERIAL E MÉTODOS}

O experimento foi conduzido no período de 10 de janeiro a 30 de julho de 2001, na Fazenda Experimental São Manuel, da Faculdade de Ciências Agronômicas, Universidade Estadual Paulista, Campus de Botucatu, localizada no município de São Manuel, Estado de São Paulo, cujas 
coordenadas geográficas são $22^{\circ} 46^{\prime} 05$ “de latitude sul e $48^{\circ} 34^{\prime} 11^{\prime \prime}$ de longitude oeste de Greenwich, a 740m de altitude.

$O$ solo, no qual foi instalado o experimento, pertence a uma faixa de solo classificada como Latossolo Vermelho Amarelo de textura média, com camada superficial de textura arenosa, sendo o relevo suave ondulado a ondulado.

Os valores dos teores de água no solo e seus respectivos potenciais, para a camada de 0 $20 \mathrm{~cm}$, com amostras deformadas, segundo Leite Júnior (2000) e Antunes (2001) foram determinados no Laboratório de Água e Solo do Departamento de Engenharia Rural da FCA/UNESP e encontram-se dispostos no Quadro 1.

Quadro 1. Valores dos teores de água no solo $\left(\mathrm{g} . \mathrm{g}^{-1}\right)$ e potencial matricial $(\mathrm{kPa})$ para a camada de $0-20 \mathrm{~cm}$.

\begin{tabular}{cc}
\hline$\Psi(\mathrm{kPa})$ & $\mathrm{U}_{0-20}\left(\mathrm{~g} \cdot \mathrm{g}^{-1}\right)$ \\
\hline-6 & 0,1242 \\
-8 & 0,1097 \\
-10 & 0,1050 \\
-30 & 0,0976 \\
-50 & 0,0755 \\
-100 & 0,0700 \\
-500 & 0,0590 \\
-1500 & 0,0550 \\
\hline
\end{tabular}

Para a condução do experimento foi utilizada uma estufa de $5,0 \mathrm{~m}$ x $20,0 \mathrm{~m}$ e altura na parte central de $2,65 \mathrm{~m}$.

Procedeu-se o estaqueamento da área com a utilização de estacas de madeira de $0,50 \mathrm{~m}$ cada, as quais foram cravadas no solo com a finalidade de demarcar a malha de amostragem estabelecida no espaçamento de $0,5 \times 1,0 \mathrm{~m}$, acrescida de quatro adensamentos de $0,25 \mathrm{~m}$ na $4^{\mathrm{a}}, 8^{\mathrm{a}}, 14^{\mathrm{a}}$ e $18^{\mathrm{a}}$ linhas. A coleta das amostras para a determinação dos teores de água do solo foi realizada em 178 pontos da área amostrada.

Foi utilizado um sistema de irrigação por gotejamento, com Fita Gotejadora Chapin "Scarcelli"; 8 mil/200 micra de espessura da parede; vazão média de $2,41 \mathrm{~L} \cdot \mathrm{h}^{-1} \cdot \mathrm{m}^{-1}$ à pressão de 10 m.c.a. e espaçamento entre gotejadores de
$20 \mathrm{~cm}$, com cinco linhas laterais de irrigação, dispostas superficialmente ao longo da estufa no sentido longitudinal ao comprimento maior da estufa.

A linha principal, de PVC com $25 \mathrm{~mm}$ de diâmetro externo, foi colocada na lateral da estufa, sendo nesta instalada uma linha de derivação com um registro geral de esfera de $3 / 4$ ", filtro de tela de aço (150 mesh), regulador de pressão para mantê-la a 10,0 m.c.a e um manômetro tipo Bourbon com glicerina para proceder a verificação. As cinco linhas laterais de irrigação foram conectadas à linha de derivação através de derivações tipo " $T$ " e presas por braçadeiras.

Para a determinação da vazão dos gotejadores e do coeficiente de uniformidade de distribuição de água do sistema de irrigação foi utilizada a pressão de 10,0 m.c.a. Utilizou-se um método proposto por Keller e Karmeli, conforme descrito por Bernardo (1995), que recomenda a obtenção das vazões em quatro pontos ao longo da linha lateral, ou seja, do primeiro gotejador, do gotejador situado a $1 / 3$ do comprimento, do gotejador situado a $2 / 3$ do comprimento e do último gotejador. As linhas laterais selecionadas para determinação, ao longo da linha de derivação devem ser a primeira linha lateral, a linha lateral situada a $1 / 3$, a situada a $2 / 3$ e a última linha lateral. Em razão do pequeno número de pontos determinados em cada linha lateral, principalmente em se tratando de linhas de maior comprimento, sugere-se a coleta de dados em oito gotejadores por linha lateral, usando o seguinte critério de seleção dos gotejadores: determinar a vazão do primeiro gotejador, dos gotejadores situados a 1/7, 2/7, 3/7, 4/7, 5/7, 6/7 e do último gotejador. As quatro linhas laterais selecionadas ao longo da linha de derivação, para a determinação, devem ser a primeira e as situadas a $1 / 3,2 / 3$ e a última.

$\mathrm{O}$ coeficiente de uniformidade de distribuição foi determinado pela seguinte equação:

$$
C U D=\frac{q_{25}}{\bar{q}} .100
$$

Onde: 
$\mathrm{q}_{25}=$ vazão média dos $25 \%$ menores valores de $\mathrm{q}_{\mathrm{i}}, \mathrm{L} \cdot \mathrm{h}^{-1}$;

$\bar{q}=$ vazão média de todos os pontos de emissão, L.h ${ }^{-1}$;

$\mathrm{q}_{\mathrm{i}}=$ vazão do i-ésimo ponto de emissão, $\mathrm{L} \cdot \mathrm{h}^{-1}$.

O manejo da irrigação foi feito com base na utilização da bateria de seis tensiômetros com manômetro de mercúrio.

Reichardt (1990) relacionou os componentes do potencial da água: componente gravitacional $\left(\Psi_{\mathrm{g}}\right)$, componente de pressão $\left(\Psi_{\mathrm{p}}\right)$ e componente matricial $\left(\Psi_{\mathrm{m}}\right)$. Ainda, Reichardt (1990) afirma que o tensiômetro é um instrumento de campo utilizado para medir diretamente $\Psi_{\mathrm{m}}$ e que:

$\Psi_{m}=-\left(13,6 h-h-h_{1}-h_{2}\right) c m H_{2} O$

ou

$\Psi_{m}=-12,6 h+h_{1}+h_{2}$

Onde:

$\mathrm{h}=$ leitura em $\mathrm{cm}$ de $\mathrm{Hg}$ (mercúrio);

$\mathrm{h}_{1}=$ altura do nível de $\mathrm{Hg}$ em relação ao solo;

$\mathrm{h}_{2}=$ profundidade de medida.

Deste modo, segundo Reichardt (1988), o potencial matricial da ordem de $-6 / 100 \mathrm{~atm}$ ($6 \mathrm{kPa}$ ) foi considerado para a determinação do ponto de capacidade de campo. Sabendo-se que $1 \mathrm{~atm}$ corresponde a $76 \mathrm{~cm}$ de $\mathrm{Hg}$ (mercúrio) e substituindo o valor de $\Psi_{\mathrm{m}}$ (potencial matricial) encontrado para $-0,06$ atm na equação (2) e medindo-se em campo, os valores de $h_{1}$ e $h_{2}$, obtém-se o valor de h, que é a leitura da coluna de mercúrio, acusada no tensiômetro. Com o correspondente valor de $\mathrm{h}$ (leitura $\mathrm{em} \mathrm{cm}$ de $\mathrm{Hg}$ ), pôde-se saber, portanto, em que momento o tensiômetro acusou a capacidade de campo. Para um solo saturado, o $\Psi_{\mathrm{m}}$ (potencial matricial) é igual a zero, e, conseqüentemente $h$ é igual a zero também.

Procedeu-se a irrigação da área, utilizando o sistema de irrigação por gotejamento com a pressão de 10 m.c.a. até que o solo atingisse o ponto de saturação. Em seguida o sistema de irrigação foi desligado para atingir a capacidade de campo.

Ao atingir a capacidade de campo, foram realizadas as três coletas para a determinação da umidade do solo em 178 pontos, nos dias 06 de julho, 18 de julho e 31 de julho de 2001, sendo que o valor da umidade considerada para a análise dos dados foi resultante da média das três coletas. As amostras foram coletadas utilizando um trado tipo holandês, na profundidade de $0-20 \mathrm{~cm}$, em seguida realizou-se a análise da umidade do solo, conforme Empresa Brasileira de Pesquisa Agropecuária (1997), pelo método da umidade atual (método gravimétrico), que tem como princípio a determinação da umidade à base de peso presente na amostra de solo, transportada em embalagem impermeável e vedada.

O procedimento para a determinação da umidade atual consistiu na coleta de amostras com estrutura deformada em lata de alumínio numerada e de peso conhecido. A seguir, foram pesadas e transferidas para estufa a $105-110^{\circ} \mathrm{C}$, por um período de $24 \mathrm{~h}$. Posteriormente, foram retiradas da estufa, colocadas em dessecador onde esfriaram e, por fim, devidamente pesadas em balança de precisão.

A umidade foi calculada através da expressão abaixo:

$U G=100(a-b) / b$

Onde:

$\mathrm{UG}=$ umidade gravimétrica (\%)

$\mathrm{a}=$ peso da amostra úmida $(\mathrm{g})$

$\mathrm{b}=$ peso da amostra seca $(\mathrm{g})$

A Figura 1 permite uma visualização do estaqueamento da estufa utilizada para a condução do experimento, com a disposição do sistema de irrigação por gotejamento e tensiômetros. 


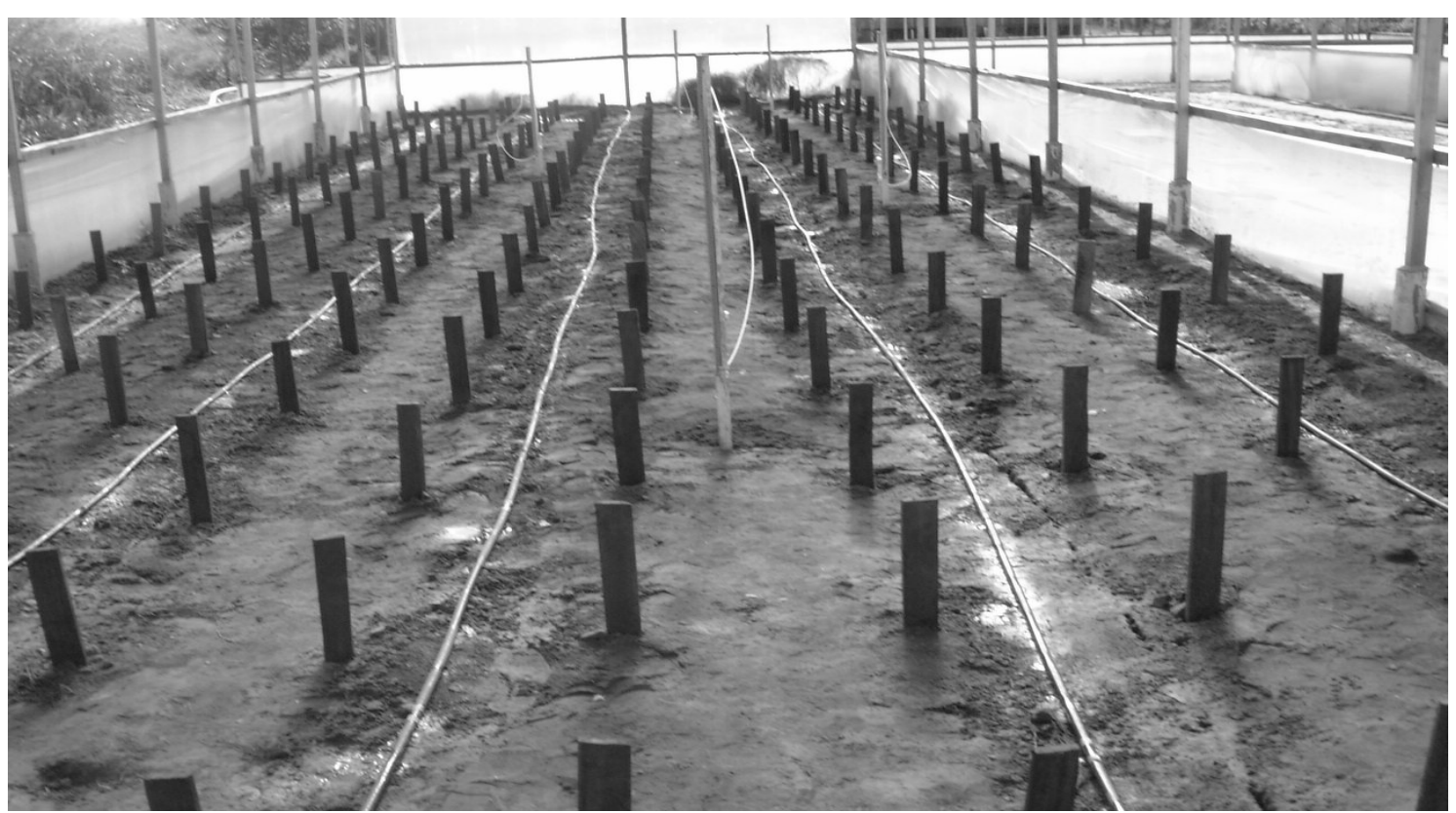

Figura 1. Vista da estufa utilizada para a condução do experimento com a disposição do sistema de irrigação por gotejamento, tensiômetros e estaqueamento.

Considerando-se uma determinada propriedade que apresente uma variação de um local para outro, com um certo grau de organização ou continuidade, caracterizado por dependência espacial, deve-se utilizar as metodologias estatísticas que considerem esta dependência nas inferências populacionais.

Assim, para o estudo da variabilidade e dependência espacial da umidade do solo, da área estudada, foram coletadas amostras em 178 pontos estabelecidos, sendo que para cada ponto foram determinadas as coordenadas espaciais, conforme técnica proposta por Isaaks \& Srivastava (1989).

A análise da dependência espacial, determinada pelo variograma foi obtida com o auxílio do Programa GS+ "Geostatistical for Environmental Sciences", Versão 5.0 (GS+, 2000), que utiliza os valores das variáveis de umidade associados as suas respectivas coordenadas de campo.

Todos os pares de amostras possíveis foram examinados e agrupados dentro de classes de distâncias ("lags") e direções aproximadamente iguais. Para esse processo, foram construídos os variogramas experimentais (DEUTSCH \& JOURNEL, 1998) e posteriormente definidos os modelos teóricos de variogramas (esférico, exponencial, gaussiano, linear e linear com patamar), os quais foram superpostos à seqüência de pontos obtidos no variograma experimental, de modo que a curva que melhor se ajustou aos pontos do variograma (até onde a curva se estabiliza) representasse a magnitude, alcance e intensidade da variabilidade espacial da variável estudada.

Matheron (1963) concretizou os fundamentos da geoestatística desenvolvendo a Teoria das Variáveis Regionalizadas, como sendo uma função espacial numérica, que apresenta uma variação de um local para outro com uma continuidade aparente, caracterizando uma certa dependência espacial. Para isso, baseou-se em conceitos de função aleatória e estacionariedade de segunda ordem.

Para a aplicação da geoestatística, é de fundamental importância o estudo da função $\gamma^{*}(h)$, conhecida como variância espacial.

A função variância espacial (equação 4) pode ser, em termos práticos, estimada por:

$$
\gamma(h)=\frac{1}{2 N(h)} \sum_{i=1}^{N(h)}\left[Z\left(x_{i}\right)-Z\left(x_{i}+h\right)\right]^{2}
$$

Onde:

$\mathrm{N}(\mathrm{h})$ é o número de pares de valores amostrados, 


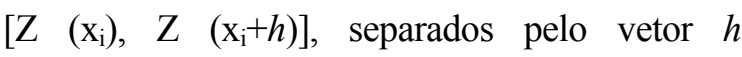
(JOURNEL \& HUIJBREGTS, 1978).

O variograma normalmente é representado pelo gráfico de $\gamma^{*}(h)$ versus $h$, isto é, semivariância do atributo versus distância Vieira et al. (1997). O gráfico $\gamma^{*}(h)$ versus $h$ é chamado de variograma experimental e expressa a variabilidade espacial entre as amostras, sendo uma função que só depende do vetor $h$, e, portanto depende da magnitude e direção de $h$.

A representação esquemática do variograma e, com características bem próximas do ideal, com os seus respectivos parâmetros $\left(\mathrm{C}_{0}\right.$, $\mathrm{C}_{0}+\mathrm{C}_{1}$ e a) é apresentada na Figura 2, conforme Takeda (2000).

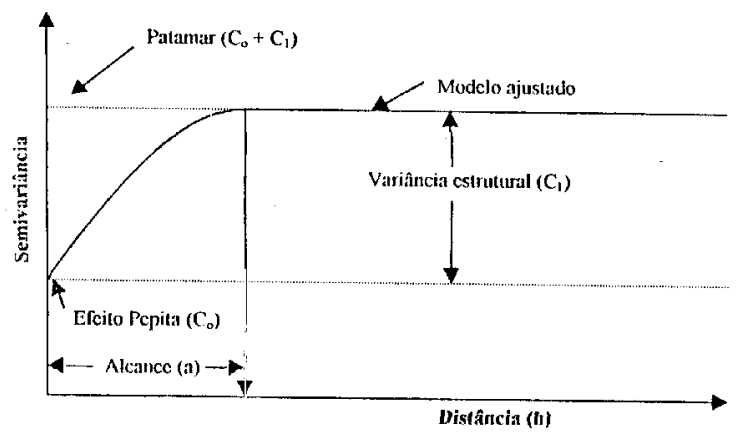

Figura 2. Representação esquemática do variograma.

As características do variograma, bem próximas do ideal, são:

\section{- $\quad$ Efeito Pepita $\left(\mathrm{C}_{0}\right)$ :}

Este valor revela a descontinuidade do variograma próximo à origem em distâncias menores do que a menor distância de amostragem (VIEIRA et al.,1983).

Quando o Efeito Pepita $\left(\mathrm{C}_{0}\right)$ for aproximadamente igual ao Patamar $\left(\mathrm{C}_{0}+\mathrm{C}_{1}\right)$, tem-se o Efeito Pepita Puro, o que demonstra uma ausência total de dependência espacial (TRANGMAR et al., 1985).

O Programa Geoestatístico GS + (GS +, 2000) propõe a seguinte relação para avaliar a \% da semivariância do efeito pepita:

$\%$ semivar. estrutural $=\frac{C}{\left(C+C_{0}\right)} .100$
Zimback (2001) adaptou os limites propostos por Cambardella et al. (1994) e considera a dependência espacial para valores $\leq$ $25 \%$ fraca; entre $25 \%$ e $75 \%$; moderada e $\geq$ $75 \%$ dependência forte. Tais índices foram considerados para a avaliação da dependência espacial.

- $\quad$ Patamar $\left(\mathrm{C}_{0}+\mathrm{C}_{1}\right)$ :

Segundo Trangmar et al. (1985), o patamar corresponde à variância da amostra $\left(\mathrm{s}^{2}\right)$ para dados estacionários. O patamar é, portanto, o ponto onde toda semivariância da amostra é de influência aleatória.

- $\quad$ Alcance (a):

A distância na qual $\gamma(\mathrm{h})$ atinge o patamar é chamada de alcance ("range") e é a distância limite de dependência espacial.

No presente estudo, foi verificada a existência ou não de anisotropia nos ângulos de $0^{\circ}, 45^{\circ}, 90^{\circ}$ e $135^{\circ}$, segundo os parâmetros propostos por Zimmerman (1993).

Através da análise do variograma, se for verificada a dependência espacial, pode-se estimar valores através do método de interpolação conhecido como krigagem, expressando os resultados em forma de mapas de isolinhas e mapas de superfícies.

Vieira et al. (1983) mostram que supondo que se queira estimar valores, $\mathrm{z}^{*}$, para todas as localizações, $x_{0}$, onde se têm valores que não foram medidos, a estimativa de um ponto qualquer $\mathrm{x}_{0}$, pertencente ao espaço amostral, é dada pelo processo de krigagem, definido por:

$z *\left(x_{0}\right)=\sum_{i=1}^{N} \lambda_{i} z\left(x_{i}\right)$

Onde:

$\mathrm{z}^{*}\left(\mathrm{x}_{0}\right)$ é o valor estimado no ponto $\mathrm{x}_{0}$;

$\mathrm{N}$ é o número de valores medidos $\mathrm{Z}\left(\mathrm{x}_{\mathrm{i}}\right)$, envolvidos na estimativa;

$\lambda_{\mathrm{i}}$ são os pesos associados a cada valor medido, $\mathrm{Z}\left(\mathrm{x}_{\mathrm{i}}\right)$.

Como método de interpolação para variáveis relacionadas ao comportamento da água, foram confeccionados os mapas 
interpolados por krigagem, da área estudada. A krigagem dos valores de umidade obtidos, que consiste numa interpolação desses valores entre os pontos amostrados, foi efetuada pelo módulo Interpolação - krigagem, do programa GS+ (GS+, 2000).

Foram utilizados também para o cálculo da krigagem, os parâmetros obtidos pela análise espacial, ou seja, o alcance, o efeito pepita e o patamar, uma vez que a krigagem é um método geoestatístico de interpolação, sendo necessário detectar a distância espacial entre as amostras, para o atributo em estudo (YOST et al., 1982).

A visualização dos resultados foi feita na forma de mapa bidimensional, através do programa $\mathrm{GS}+(\mathrm{GS}+, 2000)$.

Como o método de ajuste dos modelos de variogramas mais tradicional é o chamado "ajuste a sentimento" (RIBEIRO JÚNIOR, 1995), é necessário que se tenha uma maneira para checar se o modelo ajustado é ou não satisfatório. É necessário, portanto, validar o plano de krigagem antes de usá-la para a construção de mapas, podendo-se realizar através da validação cruzada.

A validação cruzada ("crossvalidation") foi empregada para avaliar os resultados obtidos e para isso, cada valor de dado foi eliminado e daí esse valor foi estimado usando-se informações dos dados restantes, de acordo com o método descrito por Kane et al. (1982) e Goovaerts (1997).

Ainda, segundo Goovaerts (1997), um fator que afeta o cálculo de precisão do método de interpolação é o número de vizinhos usados para a estimação. Assim, o número de amostras foi fixado em 16 (BURGESS \& WEBSTER, 1980 e KRAVCHENKO \& BULLOCK, 1999), que é o número escolhido automaticamente pelo programa, pois é o que melhor estima os pontos.

A exatidão da seleção do modelo do variograma foi medida através do erro entre os dados medidos e os valores estimados (ZHANG et al., 1995). O critério de validação cruzada empregado para selecionar o variograma foi $o$ coeficiente de determinação entre os valores obtidos e estimados (MYERS, 1991). O erro padrão de estimação avaliou quantitativamente o ajuste do variograma e os erros dele decorrentes na krigagem, utilizando-se os conceitos definidos por Davis (1987).

\section{RESULTADOS E DISCUSSÃO}

A vazão média dos gotejadores foi de $2,41 \mathrm{~L} \cdot \mathrm{h}^{-1} \cdot \mathrm{m}^{-1}$, à pressão de 10,0 m.c.a.. Utilizando-se o método proposto por Keller e Karmeli, conforme descrito por Bernardo (1995), o CUD (coeficiente de uniformidade de distribuição) encontrado foi de $97,97 \%$, ou seja, de aproximadamente $98 \%$, o que caracterizou uma ótima distribuição.

As análises espaciais foram executadas pelo módulo "Análise da semivariância" do programa GS+ (GS+, 2000), conforme descrito por Journel \& Huijbregts (1978) e Isaaks \& Srivastava (1989).

Para a confecção do variograma unidirecional, foi verificada a pouca consistência do ajuste efetuado automaticamente pelo programa considerando o pouco número de classes para as distâncias menores, por esse variograma poderia ser considerado efeito pepita puro. Procurando-se proceder a uma análise mais acurada foi verificada a existência ou não de anisotropia nos ângulos de $0^{\circ}, 45^{\circ}, 90^{\circ}$ e $135^{\circ}$, segundo os parâmetros estabelecidos por Zimmerman (1993).

$\mathrm{Na}$ Figura 3 está apresentado o variograma anisotrópico obtido para a umidade do solo para a direção $0^{\circ}$, tendo sido feito $o$ ajuste pelo modelo esférico.

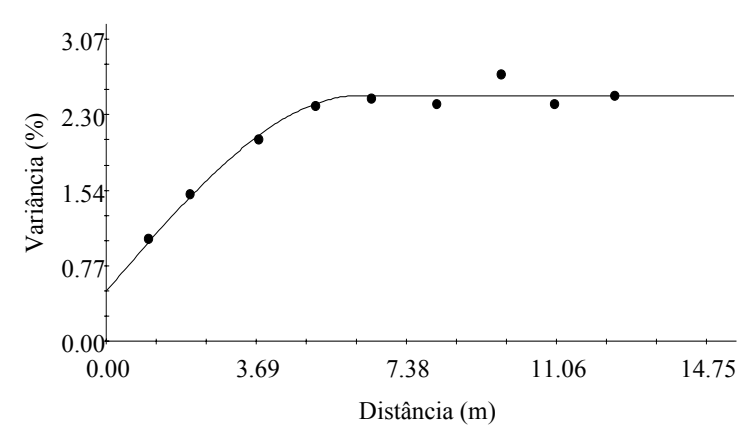

Figura 3. Variograma anisotrópico da umidade à base de peso $(\%)$ na direção $0^{\circ}$. 
Nos variogramas anisotrópicos da umidade do solo nas direções $45^{\circ}, 90^{\circ}$ e $135^{\circ}$, não foi possível ajustar modelos teóricos aos dados experimentais, provavelmente devido ao número reduzido de pontos nestas direções e também ao efeito predominante da anisotropia na direção $0^{\circ}$.

Os parâmetros obtidos pela análise variográfica, após o ajuste, para a direção $0^{\circ}$, estão apresentados no Quadro 2.

Quadro 2. Parâmetros variográficos do teor de umidade do solo.

\begin{tabular}{lc}
\hline Parâmetros & $0^{\circ}$ \\
\hline Efeito Pepita & 0,5100 \\
Patamar & 2,5000 \\
Alcance & 3,2960 \\
Proporção Espacial & 0,7960 \\
\hline
\end{tabular}

$\mathrm{Na}$ Figura 3, que apresenta o variograma anisotrópico para a umidade do solo para a direção $0^{\circ}$, pode-se notar uma dependência espacial, caracterizada como dependência alta $\left(\mathrm{C} / \mathrm{C}+\mathrm{C}_{0}=0,7960\right)$.

$\mathrm{O}$ parâmetro de alcance encontrado foi igual a $3,2960 \mathrm{~m}$, ou de, aproximadamente $3,30 \mathrm{~m}$. Segundo Guerra (1988) o alcance corresponde ao conceito da zona de influência ou dependência espacial de uma amostra, marcando a distância a partir da qual as amostras tornam-se independentes. Segundo Prevedello (1987) citado por Takeda (2000), para garantir a tão comentada independência entre os pontos amostrais tal intervalo deve ser, no mínimo, de duas vezes o valor do alcance determinado para um atributo qualquer. Desse modo, no planejamento de experimentos de irrigação, onde se almeja a independência entre observações, o intervalo de amostragem deveria ser no mínimo duas vezes o alcance. A intensidade de amostragem também poderia ser aumentada para um valor de $3 \mathrm{~m}$, já que o alcance encontrado foi aproximadamente de $3,30 \mathrm{~m}$, e não necessariamente a cada $1 \mathrm{~m}$ no sentido vertical, como foi realizada, com isso, tem-se uma redução do número de amostras, o que é de extrema importância, principalmente quando se trabalha com variáveis difíceis de serem determinadas, ou mesmo quando a sua determinação é, às vezes, onerosa.

Portanto, o alcance da dependência espacial da umidade representa a distância na qual os pontos de amostragem apresentam-se correlacionados, sendo um parâmetro de fundamental importância para planejamento e avaliações de experimentos de irrigação, não somente para determinar a intensidade de amostragem, como também ajudar no planejamento de programas de irrigação, uma vez que detecta até onde uma variável em estudo apresenta dependência espacial.

O fenômeno de anisotropia, com maior variação na direção $\mathrm{N}-\mathrm{S}$, foi similarmente descrito por Brooker \& Winchester (1995), pois ao estudarem a variação espacial da água prontamente disponível num vinhedo irrigado, observaram, através dos variogramas estudados, o fenômeno da anisotropia, sendo que a variação na direção $\mathrm{N}-\mathrm{S}$ foi bem maior do que a direção $\mathrm{E}-\mathrm{W}$. Concluíram também que este fenômeno poderia influenciar no projeto do sistema de irrigação.

Com base no modelo anisotrópico foi realizada a interpolação dos dados de umidade do solo à base de peso na profundidade de 0 $20 \mathrm{~cm}$, utilizando a krigagem ordinária pontual, a qual está representada na Figura 4.

Pela análise da Figura 4 e considerandose os valores de umidade analisados na estufa em estudo $(5,0 \times 20,0 \mathrm{~m})$, observa-se uma heterogeneidade dos mesmos, na maior parte da estufa utilizada no presente estudo. Pode-se também notar que na porção inicial da estufa, no canto inferior direito, os valores de umidade do solo são maiores e esse fato pode ser atribuído a uma maior proximidade dos gotejadores à saída de água, ou seja, ao início do sistema de irrigação, onde se tem uma menor perda de carga e uma maior distribuição de água. Já na porção final da estufa, mais precisamente no canto superior esquerdo da Figura 4, observa-se uma diminuição da umidade, o que pode ser justificável pelo fato de ser esta uma área característica de final de linha lateral do sistema de irrigação por gotejamento. 


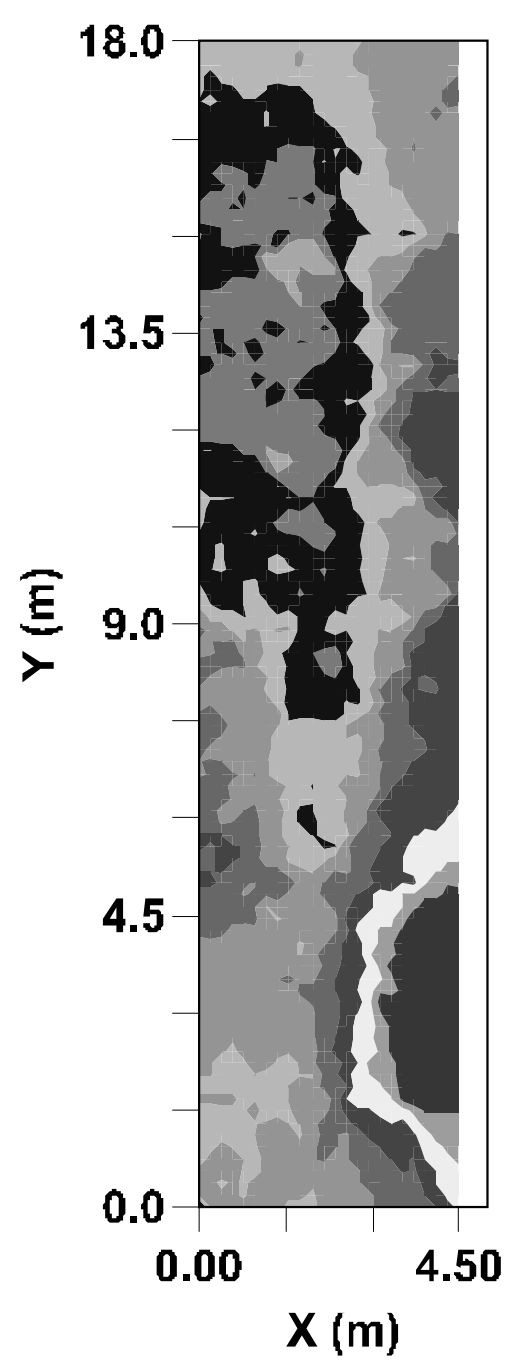

Figura 4. Representação bidimensional da krigagem da umidade do solo à base de peso.

Segundo Davis (1987), a validação cruzada é um método adequado para definir a exatidão da krigagem como interpolador. Em face ao exposto, a validação cruzada foi utilizada para avaliar a krigagem, como pode ser visualizado na Figura 5.

Pela Figura 5 pode-se verificar que os dados estimados foram muito próximos dos dados reais, comprovando que a krigagem ordinária é um bom interpolador, para estes dados.

Para a caracterização da variabilidade espacial da umidade do solo, os dados analisados permitiram consolidar a abordagem feita por Cataneo (1997), que relata a presença de variabilidade espacial nas parcelas em ambiente protegido.

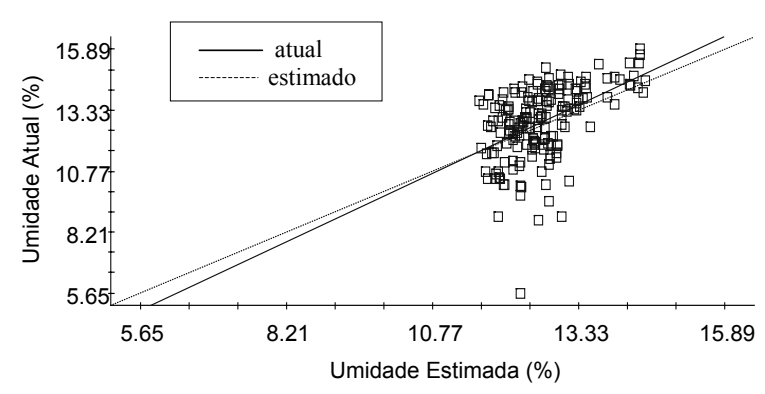

Figura 5. Validação cruzada da umidade do solo à base de peso. 
Sintetizando os dados estudados e considerando a aplicação agronômica dos mesmos, é importante ressaltar que foram extraídos relacionando água e solo, e não águasolo-planta. Para fins agrícolas, é importante adaptá-los para uma determinada cultura, onde a umidade do solo é de fundamental importância, uma vez que diferentes culturas apresentam também diferentes exigências hídricas e, portanto, lâminas de água distintas. Relacionando os dados da distribuição da umidade num sistema de irrigação por gotejamento em cultivo protegido, pôde-se valer dos mesmos para avaliar, por exemplo, a melhor distribuição do sistema de irrigação no interior da estufa, associando-o a distribuição da umidade e exigências da cultura. Desse modo, é importante o estudo da variabilidade espacial da umidade, principalmente em cultivo protegido, onde é realizado um número sucessivo de cultivos, sendo que tais dados são de aplicação a longo prazo, principalmente para condução de experimentos. Na implantação de uma cultura visando avaliar o grau e resposta a determinadas adubações, comportamento em relação a um manejo do solo específico, ou ainda, um melhoramento genético, tal estudo é interessante. É importante considerar também que o cultivo protegido é um ambiente com certas peculiaridades, quando comparado com o implantado no campo, por isso, estudos relacionando variabilidade espacial da distribuição da umidade em cultivo protegido, sob diferentes culturas seriam de vital importância.

\section{CONCLUSÕES}

Pela análise estrutural do teor de umidade do solo em sistema de irrigação por gotejamento em cultivo protegido, pode-se concluir que:

- o teor de umidade no solo apresentou distribuição espacial anisotrópica;

- no sentido do comprimento da estufa a dependência espacial foi de aproximadamente $3,30 \mathrm{~m}$, permitindo coletas de solo para determinação de umidade a distâncias maiores a $3,30 \mathrm{~m}$.

- no sentido da largura da estufa, não foi possível ajustar modelos;

- apesar do CUD (coeficiente de uniformidade de distribuição) ser de $98 \%$, utilizando a representação gráfica da superfície, observou-se maior teor de água na parte inicial e menor teor de água na parte final das linhas de distribuição de água;

- a krigagem foi um bom interpolador para mapeamento da umidade do solo.

\section{AGRADECIMENTOS}

Ao Prof. Dr. Norberto da Silva, pela concessão da estufa para a realização deste trabalho.

A todos os funcionários da Fazenda Experimental São Manuel, pela responsabilidade e profissionalismo na condução das pesquisas realizadas, em especial, ao Nilton Antonio de Moraes, José Luís Zanela, Geraldo Lourençon, Luís Antonio da Silva e Luís Antonio Gallo, agradecemos todo o auxílio recebido no estaqueamento da estufa e coleta das amostras.

\section{REFERÊNCIAS BIBLIOGRÁFICAS}

ABOUFIRASSI, M.; MARIÑO, M.A. Kriging of water levels in the Souss Aquifer, Morocco. Mathematical Geology, New York, v. 15, n. 4, p. 537-550, 1983.

ANTUNES, C.L. Fertirrigação nitrogenada por gotejamento e época de aplicação foliar de ácido giberélico $\left(\mathrm{GA}_{3}\right)$ em alface americana (Lactuca sativa L.). 2001. 120 f. Dissertação (Mestrado em Agronomia) Faculdade de Ciências Agronômicas, Universidade Estadual Paulista, Botucatu, 2001. BERNARDO, S. Manual de irrigação. 6. ed. Viçosa: Universidade Federal de Viçosa, 1995. $657 \mathrm{p}$. 
BRASIL. Ministério da Irrigação. Programa Nacional de Irrigação. Tempo de irrigar: manual do irrigante. São Paulo, 1987. 160 p.

BRESLER, E. et al. Statistical analysis of salinity and texture effects on spatial variability of soil hydraulic conductivity. Soil Science Society of America Journal, Madison, v. 48, n. 1, p. 16-25, Jan-Feb 1984.

BROOKER, P.I.; WINCHESTER, J.P. A geostatistical study of soil data from an irrigated vineyard near Waikerie, South Australia. Environment International, Elmsford, v. 21, n. 5, p. 699-704, 1995.

BURDEN, D.S.; SELIM, H.M. Correlation of spatially variable soil water retention for a surface soil. Soil Science, Baltimore, v. 148, n. 6, p. 436-447, Dec 1989.

BURGESS, T.M.; WEBSTER, R. Optimal interpolation and isarithmic mapping of soil properties, 1. The semi-variogram and punctual kriging. The Journal of Soil Science, Oxford, v. 31, n. 2, p. 315-331, Jun 1980.

CAMBARDELLA, C. A et al. Field-scale variability of soil properties in Central Iowa soils. Soil Science Society of America Journal, Madison, v. 58, n. 5, p. 1501-1511, Sep-Oct 1994.

CATANEO, A. Experimentação em ambiente protegido. In: FORO INTERNACIONAL DE CULTIVO PROTEGIDO, 1997, Botucatu. Anais...Botucatu: Universidade Estadual Paulista/Fundação de Amparo à Pesquisa do Estado de São Paulo, 1997. p. 129-153.

CIOLLARO, G.; ROMANO, N. Spatial variability of the hydraulic properties of a volcanic soil. Geoderma, Amsterdam, v. 65, n. 3-4, p. 263-282, Mar 1995.

DAVIDOFF, B.; SELIM, H.M. Correlation between spatially variable soil moisture content and soil temperature. Soil Science, Baltimore, v. 145, n. 1, p. 1-10, Jan 1988.

DAVIS, B.M. Uses and abuses of crossvalidation in geostatistics. Mathematical Geology, New York, v. 19, n. 3, p. 241-248, 1987.

DELLA VECCHIA, P.T.; KOCH, P.S. História e perspectivas da produção de hortaliças em ambiente protegido no Brasil. Informe Agropecuário, Belo Horizonte, v. 20, n. 200/201, p. 5-10, Set-Dez 1999.
DEUTSCH, C. V.; JOURNEL, A. G. GSLIB. geostatistical software library. New York: Oxford University Press, 1998, Não paginado. EMPRESA BRASILEIRA DE PESQUISA AGROPECUÁRIA. Centro Nacional de Pesquisa de Solos. Manual de método de análises de solo. Rio de Janeiro, 1997. 212 p. FOLEGATTI, M. V. Estabilidade temporal e variabilidade espacial da umidade e do armazenamento de água em solo siltoso. 1996. 84 f. Tese (Livre-Docência) - Escola Superior de Agricultura "Luiz de Queiroz", Universidade de São Paulo, Piracicaba, 1996.

GOOVAERTS, P. Geostatistics for natural resources evaluation. New York: Oxford University Press, 1997. 650 p.

GOTO, R. Plasticultura nos trópicos: uma avaliação técnico-econômica. Horticultura Brasileira, Brasília, v. 15, p. 163-165, 1997. Suplemento.

GS+. GS+. Geostatistical for environmental sciences: version 5.0. Michigan: Gamma Design Software, 2000.

GUERRA, P. A. G. Geoestatística operacional. Brasília: Departamento Nacional da Produção Mineral/Ministério de Minas e Energia, 1988. 145 p.

ISAAKS, E.H.; SRIVASTAVA, R.M. An introduction to applied geostatistics. New York: Oxford University Press, 1989. 600 p. JOURNEL, A. C.; HUIJBREGTS, C. J. Mining geostatistics. London: Academic Press, 1978. $600 \mathrm{p}$.

KANE, V.E. et al. Interpretation of regional geochemistry using optimal interpolation parameters. Computers \& Geosciences, Elmsford, v. 8, n. 2, p. 117-135, 1982.

KRAVCHENKO, A. N.; BULLOCK, D. G. A comparative study of interpolation methods for mapping soil properties. Agronomy Journal, Madison, v. 91, n. 3, p. 393-400, May-Jun, 1999.

LEITE JÚNIOR, J.B. Dessalinização do solo provocada pelo excesso do íon potásssio em latossolo vermelho amarelo cultivado com alface americana (Lactuca sativa $\mathbf{L}$.) irrigada sob ambiente protegido. 2000. $80 \mathrm{f}$. Dissertação (Mestrado em Agronomia) Faculdade de Ciências Agronômicas, Universidade Estadual Paulista, Botucatu, 2000. 
MALLANTS, D. et al. Spatial variability of hydraulic properties in a multi-layered soil profile. Soil Science, Baltimore, v. 161, n. 3, p. 167-181, Mar 1996.

MATHERON, G. Principles of geostatistics. Economic Geology, Lancaster, v. 58, n. 10, p. 1246-1266, 1963.

MYERS, D. E. Interpolation and estimation with spatially located data. Chenometrics and Intelligent Laboratory Systems, Amsterdam, v. 11, n. 3, p. 209-228, Oct 1991.

NIELSEN, D.R.; BIGGAR, J.W.; ERH, K.T. Spatial variability of field-measured soil-water properties. Hilgardia, Berkeley, v. 42, n. 7, p. 215-260, Nov 1973.

REICHARDT, K. Capacidade de campo. Revista Brasileira de Ciência do Solo, Campinas, v. 12, n. 3, p. 211-216, Set-Dez 1988.

REICHARDT, K. O solo como um reservatório de água. In: . A água em sistemas agrícolas. Piracicaba: Manole, 1990. cap. 3, p. 27-69.

RIBEIRO JÚNIOR, P.J. Métodos geoestatísticos no estudo da variabilidade espacial de parâmetros do solo. 1995. 99 f. Dissertação (Mestrado em Agronomia) - Escola Superior de Agricultura "Luiz de Queiroz", Universidade de São Paulo, Piracicaba, 1995.

SALES, L.E.O. Variabilidade espacial da velocidade de infiltração básica associada a propriedades físicas das camadas superficial e subsuperficial de dois solos da Região de Lavras (MG). 1992. 104 f. Dissertação (Mestrado) - Escola Superior de Agricultura de Lavras, 1992.

SGANZERLA, E. Nova agricultura: a fascinante arte de cultivar com os plásticos. 6.ed. Guaíba: Agropecuária, 1997. 341 p.

SISSON, J.B.; WIERENGA, J. Spatial variability of steady-state infiltration rates as a stochastic process. Soil Science Society of America Journal, Madison, v. 45, n. 4, p. 699704, Jul-Aug 1981.
TAKEDA, E. Y. Variabilidade espacial de atributos físicos e químicos de uma associação de solos sob a videira (Vitis vinífera, L.) em Vitória Brasil-SP. 2000. 102 f. Dissertação (Mestrado em Agronomia) Faculdade de Engenharia de Ilha Solteira, Universidade Estadual Paulista, Ilha Solteira, 2000.

TRANGMAR, B. B.; YOST, R. S.; UEHARA, G. Application of geostatistics to spatial studies of soil properties. Advances in Agronomy, Orlando, v. 38, n. 1, p. 45-94, 1985.

VIEIRA, S.R. et al. Geostatistical theory and application to variability of some agronomical properties. Hilgardia, Berkeley, v. 51, n. 3, p. 1-75, Jun 1983.

VIEIRA, S.R. et al. Scaling of semivariograms and the kriging estimation of field-measured properties. Revista Brasileira de Ciência do Solo, Viçosa, v. 21, n. 4, p. 525-533, Out-Dez 1997.

VOLTZ, M.; GOULARD, M. Spatial interpolation of soil moisture retention curves. Geoderma, Amsterdam, v. 62, n. 1-3, p.109123, Mar 1994.

YOST, R. S.; UEHARA, G.; FOX, R. L. Geostatistical analysis of soil chemical properties of large land areas. II. Kriging. Soil Science Society of America Journal, Madison, v. 46, n. 5, p. 1033-1037, Sep-Oct 1982.

ZHANG, R. et al. Geostatistical analyses of trace elements in soils and plants. Soil Science, Baltimore, v. 159, n. 6, p. 383-390, Jun, 1995.

ZIMBACK, C.R.L. Análise espacial de atributos químicos de solos para fins de mapeamento da fertilidade do solo. 2001. 114 f. Tese (Livre-Docência) - Faculdade de Ciências Agronômicas, Universidade Estadual Paulista, Botucatu, 2001.

ZIMMERMAN, D. L. Another look at anisotropy in geostatistics. Mathematical Geology, New York, v. 25, n. 4, p. 453-470, 1993. 